\title{
CAR T cell therapy: A new era for cancer treatment (Review)
}

\author{
RIMJHIM MOHANTY, CHITRAN ROY CHOWDHURY, SOLOMON AREGA, \\ PRAKRITI SEN, POOJA GANGULY and NILADRI GANGULY
}

\begin{abstract}
Cancer Biology Laboratory, School of Biotechnology, Kalinga Institute of Industrial Technology (KIIT) University, Bhubaneswar, Odisha 751024, India
\end{abstract}

Received April 9, 2019; Accepted August 12, 2019

DOI: 10.3892/or.2019.7335

\begin{abstract}
Cancer has recently been identified as the leading cause of mortality worldwide. Several conventional treatments and cytotoxic immunotherapies have been developed and made available to the market. Considering the complex behavior of tumors and the involvement of numerous genetic and cellular factors involved in tumorigenesis and metastasis, there is a need to develop a promising immunotherapy that targets tumors at both the cellular and genetic levels. Chimeric antigen receptor (CAR) $\mathrm{T}$ cell therapy has emerged as a novel therapeutic $\mathrm{T}$ cell engineering practice, in which $\mathrm{T}$ cells derived from patient blood are engineered in vitro to express artificial receptors targeted to a specific tumor antigen. These directly identify the tumor antigen without the involvement of the major histocompatibility complex. The use of this therapy in the last few years has been successful, with a reduction in remission rates of up to $80 \%$ for hematologic cancer, particularly for acute lymphoblastic leukemia (ALL) and non-Hodgkin lymphomas, such as large B cell lymphoma. Recently, anti-CD19 CAR therapy, or UCART19, has been shown to be efficacious in treating relapsed/refractory hematologic cancer. Several other cell surface tumor antigens, such as CD20 and CD22, found in the majority of leukemias and lymphomas are considered
\end{abstract}

Correspondence to: Dr Niladri Ganguly, Cancer Biology Laboratory, School of Biotechnology, Kalinga Institute of Industrial Technology (KIIT) University, Campus-11, Patia, Bhubaneswar, Odisha 751024, India

E-mail: niladri.ganguly@kiitbiotech.ac.in; toniladri@gmail.com

Abbreviations: ALL, acute lymphocytic leukemia, CLL, chronic lymphocytic leukemia; CAR, chimeric antigen receptor; TCR, T cell receptor; mAb, monoclonal antibody; NK, natural killer; FDA, The United States Food and Drug Administration; scFv, single-chain variable fragment, CRISPR, clustered regularly interspaced short palindromic repeats; PAM, protospacer adjacent motif; Treg, regulatory T cell; PD-1, programmed death 1; PD-L1, programmed death-ligand 1 ; CTLA-4, cytotoxic $\mathrm{T}$ lymphocyte-associated protein 4; ICOS, inducible T-cell costimulator; CR rate, complete response rate to the treatment or disappearance of cancer

Key words: chimeric antigen receptor $\mathrm{T}$ cell therapy, NK-CAR therapy, CRISPR-CAR, bispecific CAR, tandem CAR, inhibitory CAR potential targets by pharmaceutical companies and research organizations, and trials have been ongoing in this direction. Although this therapeutic regimen is currently confined to treating hematologic cancer, the increasing involvement of several auxiliary techniques, such as bispecific CAR, Tan-CAR, inhibitory-CAR, combined antigens, the clustered regularly interspaced short palindromic repeats gene-editing tool and nanoparticle delivery, may substantially improve its overall anticancer effects. CAR therapy has the potential to offer a rapid and safer treatment regime to treat non-solid and solid tumors. The present review presents an insight into the advantages and the advances of CAR immunotherapy and presents the emerging discrepancy of CAR therapy over usual forms of therapy, such as chemotherapy and radiotherapy.

\section{Contents}

1. Introduction

2. CAR T cell therapy

3. Architectural ideology of $\mathrm{T}$ cell engineering and CAR design

4. Mode of delivery

5. Challenges of CAR T cell therapy

6. Advanced features of CAR T cell therapy

7. Advantages of CAR therapy over other therapies

8. CAR T cell therapy trials for solid tumors

9. Success rates of approved therapies

10. Future prospects

\section{Introduction}

Chimeric antigen receptors (CARs) are unique receptors that are designed to target a specific tumor antigen to functionally reprogram $\mathrm{T}$ lymphocytes. As T lymphocytes are genetically engineered to express these artificial receptors to target cancer cells, the type of therapy may be termed immunotherapy, gene therapy or cancer therapy (1). The human defense system can efficiently identify self and non-self molecules, including bacteria, viruses and abnormal cancer cells. The identification of tumor cells is based on their acquired antigenicity and immunogenicity via the expression of foreign antigens (2). However, cancer cells have the potential to subvert the immune system to their advantage, resulting in inadequate antitumor immunity, 
and tumor survival and progression (3). Immunotherapy is also termed biotherapy as the immune system in the body is naturally capable of detecting pathogens and cancerous cells. In recent years, immunotherapy has emerged as an important branch of treatment for similar types of disease; however, its protective mechanism may differ (4). Certain immunotherapies boost the immune system, whereas others directly target the cancer cells. Each treatment type has its advantages and disadvantages depending on the disease type (5). Tisagenlecleucel (Kymriah) is a medication used to treat patients with acute lymphoblastic leukemia (ALL) up to the age of 25 years. Similarly, axicabtagene ciloleucel (Yescarta) is approved for patients with large B-cell lymphoma, such as non-Hodgkin lymphoma (NHL), and those with cancer in a refractory and recurrent state or whose cancer is non-responsive to other treatments (6). With increasing awareness of the immune system, a number of innovative immunotherapies are being developed using methods which include inducing the immune system to function in an impertinent manner to target malignant cells. Another approach involves the administration of immune components, such as synthetic, modified immune proteins that are genetically engineered to target tumor antigens (7).

CAR T cell treatment has achieved success in treating hematopoietic malignancies; however, its effectiveness against solid tumors remains to be determined. In the following sections, the rapid progression in implementing the adoptive transfer of $\mathrm{T}$ cells and their mechanism of tumor cell eradication are discussed.

\section{CAR T cell therapy}

CAR is an emerging immunotherapy for several malignancies. This therapeutic approach is an experimental form of gene therapy that redirects $\mathrm{T}$ lymphocytes to eradicate cancerous cells. The initial step in this therapy is leukapheresis or the isolation of a patient's peripheral blood $(8,9)$. Apheresis is widely used to isolate blood from patients and separate it into its components, which are then genetically altered before re-injecting them into the patient's body. Currently, apheresis is used by blood banks to collect platelets and other blood components for the treatment of several diseases, including hematologic and renal disorders. Therefore, it is regarded as a safe practice for healthy individuals and patients (10) (Fig. 1).

\section{Architectural ideology of $T$ cell engineering and CAR design}

The uniqueness of chimeric receptors exists in their ability to fuse or split discrete vital functions, such as recognition, co-stimulation and activation, in different chains of a receptor molecule by imitating the complexity of the native $\mathrm{T}$ cell receptor (TCR) structure (11). T cells do not usually require costimulation for activation and to initiate proliferation, but in the process of establishing CAR T cells, the activation and proliferation of $\mathrm{T}$ cells require the presence of costimulatory molecules, which also assist in CAR $\mathrm{T}$ cell cytokine production. The strategy involves constructing an engineered chimeric receptor for $\mathrm{T}$ cells based on the integration of $\mathrm{scFv}$ fragments in the hinge area that separates scFv from the cell membrane. The exposure of scFv on the cell surface, in addi- tion to other small functional molecules, enhances induction of the cytolytic function of the engineered $\mathrm{T}$ cell. Together, this coordination of a 'living drug' in the immune system fights against cancer (12). In addition, CAR T cells can remain stable for several years in the body as long-term memory cells. This feature allows them to recognize and kill cancer cells encountered in the circulation in the case of relapse. Another advantage of CAR T cells is that they specifically target only tumor cells and not auto-antigens. Therefore, it is safe and nonlethal to host cells (13). Once the synthetic immunoreceptor is expressed on the surface of an engineered $\mathrm{T}$ cell, its $\mathrm{scFv}$ specifically binds to target antigens expressed on a cancer cell. This binding subsequently results in the transduction of an activating signal into the genetically edited immune cell. The $\mathrm{T}$ cell then elicits its effector anticancer function (14). CAR T cell therapy is considered to be the first approach to reconfigure $\mathrm{T}$ lymphocytes with an antibody-specific scFv fragment obtained from monoclonal antibodies (mAbs) by replacing different parts of the TCR $\alpha$ and $\beta$ chains. A recent report stated the potential of CAR $\gamma \delta$ T cells in curing mucosal-derived malignant tumors as a novel strategy for CAR T cell therapy (15). The hybrid TCR functionally expresses and recognizes the analogous target antigen molecules in a non-MHC-restricted manner. Depending on the diverse biomarker selection and structural complexity, different generations of CAR model have been developed (16).

First-generation CARs. The first-generation CAR T model comprises a $\mathrm{CD} 3 \zeta$ chain as a key transmitter of signals from endogenous TCRs. Following a successful outcome in pre-clinical trials, this type of drug entered into phase I clinical trials for leukemia, lymphoma and various other types of cancer, including ovarian cancer and neuroblastoma (17). Despite the inadequate antitumor action owing to the lack of activation, persistent exposure to the tumor environment has resulted in continued therapeutic effects in patients with B-cell lymphoma infused with $\alpha$-CD20-CD3 $\zeta$ CAR T cells and a number of patients with neuroblastoma treated with scFv-CD3 $\zeta$ CAR T cells (18). The heavy and light chains constitute structural parts of the B cell receptor or antibodies, called $\mathrm{scFv}$, which are fused to the $\mathrm{CD} 3$ domain or T cell-activating $\zeta$ chain of the TCR to create non-MHC-restricted activating receptor molecules. These modified molecules are capable of enhancing $\mathrm{T}$ cell antigen detection and cytotoxicity by specifically targeting tumor cells (19). The original 'true' CAR was designed by integrating an $\mathrm{scFv}$ antibody receptor directly with the $\mathrm{CD} 3 \zeta$ domain. This model was subsequently named the ' $\mathrm{T}$ body approach' and these synthetic signaling receptors are now known as CARs or chimeric immune receptors (20).

Second-generation CARs. The success of first-generation CARs in phase 1 clinical trials paved the way for second-generation CAR T cell therapy. This model of CAR T cells was established to elicit a more effective anti-leukemic response in phase I clinical trials with complete remission rates of up to $90 \%$ in patients with recurrent B-cell ALL (B-ALL). Here, the second-generation anti-CD19 $\mathrm{T}$ cells were integrated into a 4-1BB or CD28 co-stimulatory domain attached to the CD3 domain (21). However, significant concerns remain regarding 


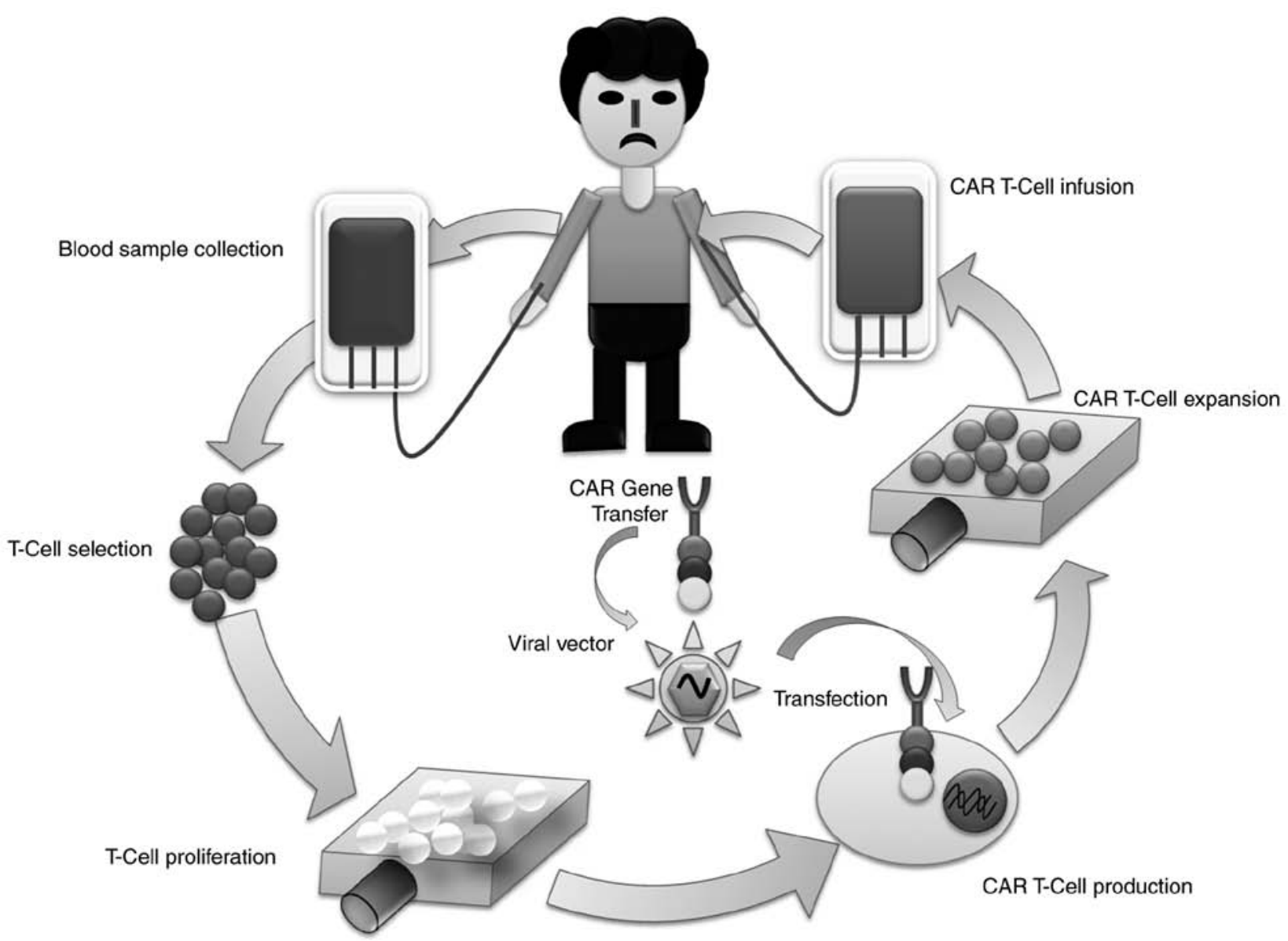

Figure 1. Adoptive CAR T cell therapy. CAR T cell therapy can be defined as a treatment in which a patient's T cells are genetically modified in the laboratory to kill cancer cells. The mechanism of adoptive CART-cell therapy includes the following steps: Collection of patient blood, isolation of T cells from the peripheral blood sample by the process of leukapheresis, transduction of cells by a vector encoding the CAR gene, expansion of CAR T cells in vitro and introduction into the patient to fight against cancer. CAR, chimeric antigen receptor.

its efficacy and safety and making it more robust. Anticipating these concerns, second-generation CARs aimed at integrating intracellular signaling domains from different co-stimulatory molecules, such as CD28, 4-1BB or CD137, inducible T cell costimulator (ICOS) or CD278, OX40 or CD134 fused to the cytoplasmic tail of the CAR, thus amplifying the signal (22). First-generation CARs contain a CD3 $\zeta$ chain as a key transmitter of signals from endogenous TCRs, whereas second-generation CARs contain a CD3 $\zeta$ chain and a single costimulatory molecule, which is why the receptor is known as a second-generation CAR. For example, anti-CD19 CARs consisting of $4-1 \mathrm{BB}$ or CD28 signaling domains produced notable complete response (CR) rates in patients with relapsed and refractory B-cell malignancies (23). CR represents complete response or disappearance of all signs of cancer in response to treatment [The United States Food and Drug Administration (FDA) 2007]. Consequently, CD28-based CARs have a rapid proliferative reaction, thus enhancing $\mathrm{T}$ effector cell functions, whereas 4-1BB-based CARs lead to improved $\mathrm{T}$ cell accumulation (24).

Third-generation CARs. To extend the antitumor efficacy, third-generation CARs comprise two signaling domains and the CD3 $\zeta$ chain, such as CD3 $\zeta-C D 28-O X 40$ and CD3 $\zeta-C D 28-4-1 B B$, to achieve improved activation signal, prolonged proliferation, elevated cytokine production and effective function (25). For example, a third-generation CAR consisting of $\alpha-C D 19-C D 3 \zeta-C D 28-4-1 B B$ reported complete remission rates by infiltrating and lysing cancer tissue in patients with chronic lymphocyte leukemia (26). In addition, certain CAR T cells function as memory cells, thus preventing tumor relapse. Despite the significant curative effect, the irrepressible activity of CARs and their increased antitumor efficacy is associated with life-threatening and unfavorable outcomes, with increased secretion of pro-inflammatory cytokines, multi-organ dysfunction, pulmonary failure and death (27).

Fourth-generation CARs. All earlier CARs were based on a precise stratagem and helped in mediating the $\mathrm{T}$ cell anticancer response. However, these suffered from limitations, including a lack of antitumor activity against solid tumors owing to large phenotypic heterogeneity and deterioration attributed to antigen-negative cancer cells. These shortcomings led to the development of a novel CAR stratagem (28). The fourth-generation CAR was introduced to establish the tumor background via the inducible expression of transgenic immune modifiers, such as interleukin (IL)-12, which activate innate immune cells and enhance $\mathrm{T}$ cell activation to reduce antigen-negative cancer cells in the marked lesion $(29,30)$ (Fig. 2). 


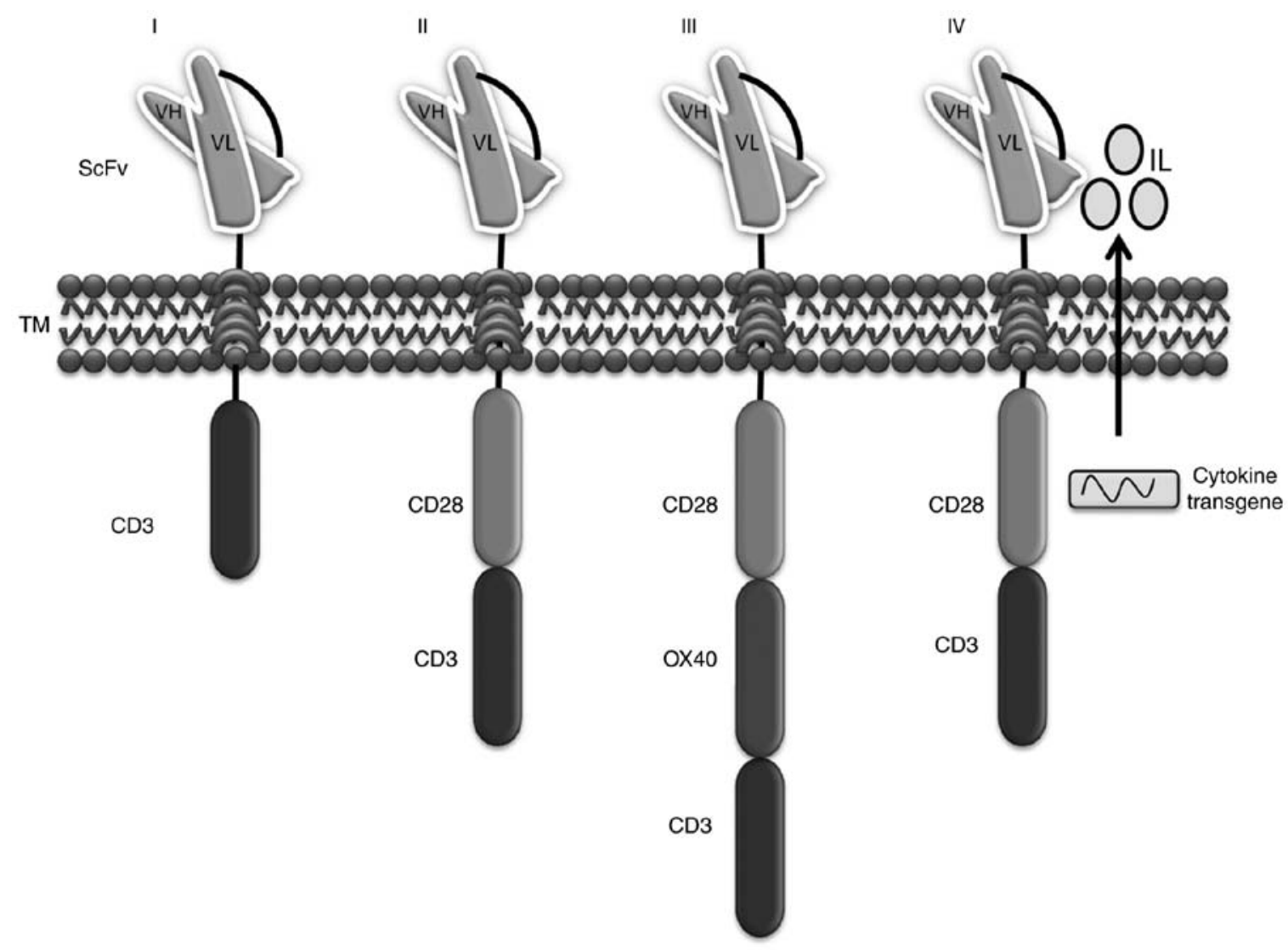

Figure 2. Architectural evolution of CAR T cell design. The CAR is constructed from the extracellular antigen-binding domain derived from monoclonal antibody (scFv) and intracellular signaling domains, linked by a hinge and a transmembrane domain. First-generation CARs contain the CD3ร chain of the T cell receptor complex, whereas second-generation receptors contain one costimulatory molecule (CD28) and third-generation CARs contain two costimulatory molecules, respectively, such as CD28 and OX40. CARs are usually introduced into primary T cells using a vector. CD3 $\zeta$ usually maintains the cytotoxic effector function of CAR-T cells. CD28 (blue) is important for T cell proliferation and cytokine secretion. 4-1BB (purple) is another co-stimulatory domain that promotes T cell survival and in vivo T cell persistence. Each CAR generation increases in complexity relating to the addition of costimulatory molecules or the induced promoter for cytokine IL-12 in fourth-generation CAR, CAR, chimeric antigen receptor; scFv, single-chain variable fragment; IL, interleukin; $\mathrm{TM}$, transmembrane.

\section{Mode of delivery}

Gene therapy involves the delivery of DNA into cells and this can be accomplished using a number of methods summarized below. The most traditional method utilizes recombinant viruses (also known as viral vectors), biological nanoparticles and non-viral methods based on the direct delivery of naked DNA.

Viral vector. Viral vectors, such as $\gamma$-retrovirus, lentivirus and adenovirus vectors are generally used in gene therapy. Retrovirus transduction is one of the commonly used delivery methods in gene therapy. The method involves a reverse transcriptase that promotes the stable integration of artificial genes into the host genome (31). To create a vector, $\gamma$-retroviral coding sequences are substituted by a gene of interest. The retroviral vectors possess an innate capability to disturb the genomic section and results in neoplastic transformation. Thus, $\gamma$-retroviral vectors have been used in gene therapy applications (32). Lentiviral vectors are retroviruses derived from human immunodeficiency virus-1, which serve as a major tool for the delivery of transgenes into mammalian cells. The advantage of using lentivirus vectors is their efficient transduction and their stable integration and expres- sion into non-dividing and dividing cells both in vitro and in vivo (33).

\section{Non-viral delivery methods}

Transposon transfection. The mechanism of transposon transfection is different from that of viral transfection. Delivery via transposons is a non-viral process that uses transposon DNA and a transposase enzyme for stable gene transfer. Two important vectors, namely piggyBac (PB) and sleeping beauty (SB), are frequently used (34). Transposons shift from one gene position to another position via a cut-and-paste mechanism. The mechanism of the transposon system using SB and PB involves four steps: i) The transposase enzyme helps in recognition and binding to the transposon; ii) a synaptic complex is produced by the coupling and binding of the repeat elements at both ends of the transposon; iii) the transposon excises the genetic element to be transposed, and iv) the excised element is reintegrated into the target location (35). The transposase for both vectors (SB and PB) consists of the DNA-binding domain, transposable catalytic domain and nuclear localization signal. The SB vector is a safer substitute for viral vectors owing to its innately low enhancer activity, non-pathogenic source and minimum epigenetic alterations at the incorporation site (36). By contrast, the $\mathrm{PB}$ vector has been shown to provide a large load capacity and 
additional competent transposition action in in vivo studies. PB vector-mediated CAR T therapy is considered safer than that based on the SB vector. Therefore, use of the $\mathrm{PB}$ vector results in greater CAR production, as evident from the production of CAR targeting CD19 using a PB vector (37).

Electroporation. Electroporation has evolved as a useful technique for modifying genes of diverse cell types. The target cells are exposed to electric fields to temporarily disrupt their cell membranes. This allows the charged molecules to enter the cells. Square-wave and pulse-based systems are new electroporation devices (38). The Lonza Nucleofector II Electroporator performs effective genetic alteration of $\mathrm{T}$ cells using certain electric parameters and electroporation buffers (39). The electroporation of human $\mathrm{T}$ cells has been reported to be associated with $\sim 40-60 \%$ of gene expression and $80 \%$ of cell viability (40). One of the limitations of electroporation is the low transfection efficiency and redundant cell damage (41).

Nanoparticles. The most critical step in CAR T cell therapy is $\mathrm{T}$ cell activation, for which cells need to be incubated with the viral vector including a CAR gene. However, stable insertional mutagenesis can be dangerous as its possible effects on humans remain to be fully elucidated (42). Retroviral or lentiviral vectors offer permanent gene integration into host cells, with the potential integration in close proximity with a proto-oncogene which can result in an oncogene. The various disadvantages associated with these transfer methods suggest that a safer alternative is needed (43).

The study by Smith et al elucidated the use of nanotechnology to resolve the tumor-targeting problem and make the therapy cost-effective. They reported that polymeric nanocarriers can efficiently deliver leukemia-specific CAR genes targeted to specific ligands on the host T cells in situ (44). A number of nanoparticles used for gene delivery have been investigated preclinically and reported. For example, magnetic nanoparticles, such as $\mathrm{Fe}_{3} \mathrm{O}_{4}$, integrate into the cell-penetrating peptide complexes. These oligonucleotides maintain stable cell transfection and plasmid transfection in addition to gene silencing and splice correction (45). A recently published study by Smith et al at the Fred Hutchinson Cancer Research Center, Seattle, confirmed that polymeric nanoparticles carrying DNA effectively introduced CAR genes into T cell nuclei and recognized leukemia cells distinctively (46). The use of nanoparticles to replace viral vectors for gene delivery has proved advantageous, as evident from the restriction of unspecific pro- or anti-inflammatory effects or pro- or antiproliferation effects (47).

\section{Challenges of CAR T cell therapy}

Although CAR therapy has emerged as a promising anticancer approach, it is not free from challenges that require optimization. For example, the enhanced persistence and improved cytotoxic profile of CAR T cell therapy are active areas of research requiring long-term follow-up in clinical trials (48). In addition, a number of serious side effects have been known to be frequently associated with CAR T cell therapy, including neurological toxicity, cytokine release syndrome (CRS), B cell aplasia, tumor lysis syndrome and anaphylaxis (49). The proliferation of CAR T cells produces cytokines in the body which kill cancer cells. The symptoms of CRS-associated toxicity range from mild symptoms of fatigue, nausea, headache, fever and chills to serious symptoms including a lowering of blood pressure, tachycardia and capillary leakage. Another side effect is the presence of CAR T cells targeting antigens on the surface of B cells or T cells that not only target cancer cells but also normal cells (50), resulting in B cell aplasia. Therefore, a thorough investigation is essential to measure the properties of B cell aplasia. Similarly, tumor lysis syndrome can result in toxicity by the collapse of dead cells generally in the beginning of cancer treatment. It could also cause organ damage and be life-threatening to the patient (51).

\section{Advanced features of CAR T cell therapy}

Although cancer cells have multiple lineages and heterogeneity, they possess common target antigens, such as CD19, CD20, CD22 and numerous others that allow CAR T cells to recognize tumor cells irrespective of cell lineage. Therefore, recent advances in this technique include more precise target antigens expressed by tumor cells $(13,52)$. This review places additional emphasis on new studies of CAR T cell therapy that distinguish diverse CAR T cells which can enhance tumor cell death. Certain models are already being implemented and others are in the clinical investigation status, including NK-CAR and clustered regularly interspaced short palindromic repeats (CRISPR)-CAR therapy (Fig. 3A-E).

Bispecific CARs. A bispecific receptor is one that contains two distinct antigen recognition domains attached and placed with two distinct intracellular signaling domains that are expressed as two different CARs on a single cell surface. At present, bispecific CAR CD19/CD20 has been introduced as a novel synthetic molecule that can recognize and bind to more than one targeted tumor antigen on the cancer cell surface. Therefore, it can create a synergistic cascade of effector molecules when it encounters two tumor antigens (53). Additionally, the bispecific CAR conserves the cytolytic capacity of T cells, i.e., if one of the objective molecules is not accessible to CAR T cells due to a cellular hindrance such as mutation of a target antigen or loss of the target antigen commonly found in malignant cells, a bispecific CAR can counterbalance the tumor evasion (54). Investigated therapeutics include CD3 of T cells and tumor antigens, such as CD19, on malignant cells. The curative ability is evident from blinatumomab, an approved bispecific $\mathrm{T}$ cell-engager against relapsed/refractory B-ALL (55). Positive results have been reported in patients $<15$ years of age with relapsed/refractory ALL, with a heightened response in 26/36 (72\%) patients in 9 months. Blinatumomab was discovered while studying a patient who was negative for minimal residual disease (MRD) and who was found to be MRD-positive following consolidated chemotherapy (56). Numerous other bispecific CARs have been investigated preclinically by several research organizations, including CD20/CD19 and CD20/CD3 (57,58). Targeting T cells with bispecific CARs was shown to eliminate transplanted pediatric ALL in a study, whereas T cells targeted by CD20 CAR did not control the disease (59). 


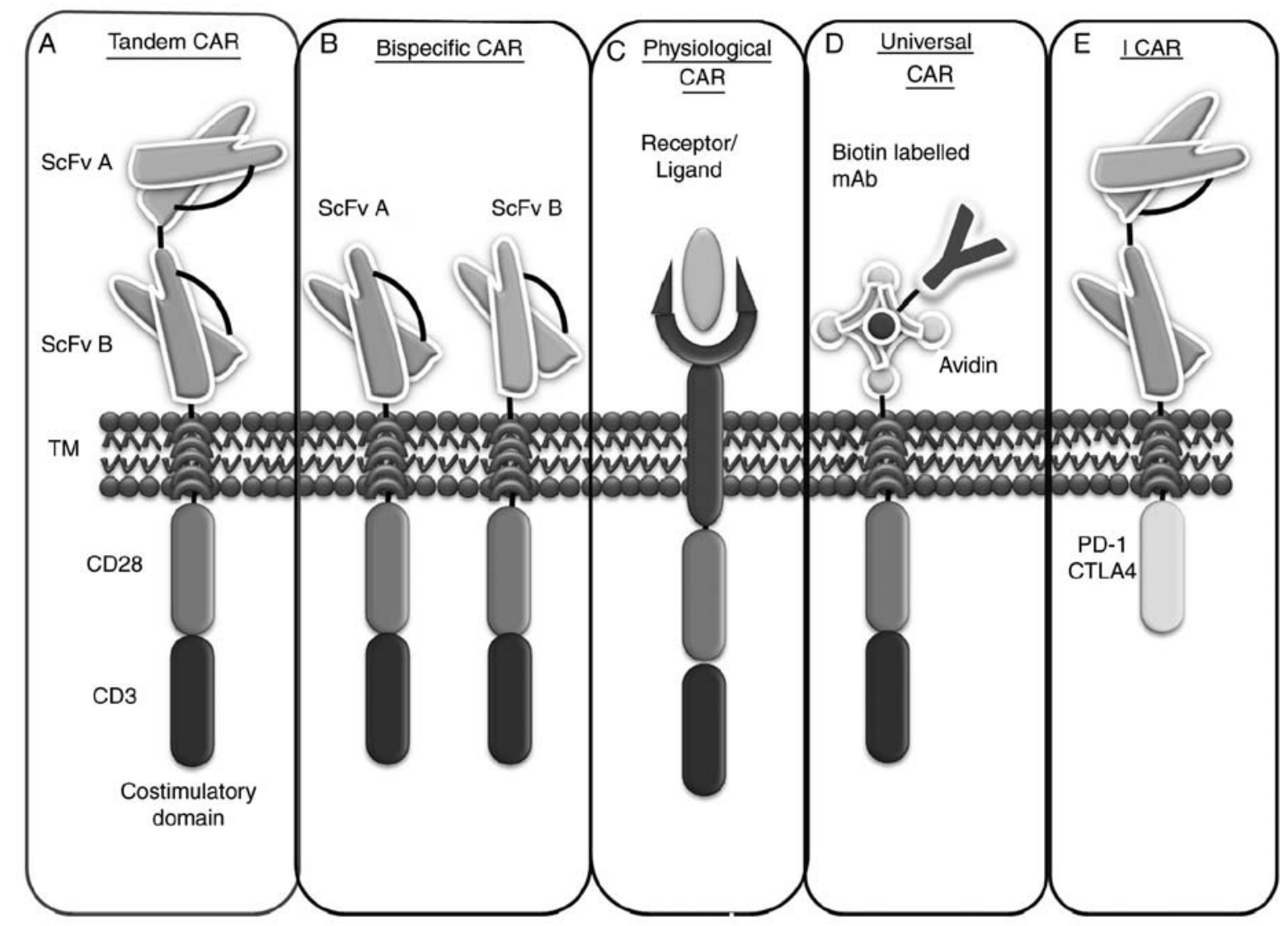

Figure 3. Advanced models of CAR T cells. (A) Tandem CAR: A single CAR structure targets two tumor antigens with a distinct antigen recognition domain (scFv) linked consecutively with a single intracellular domain. (B) Bispecific CAR: Two CARs are expressed simultaneously targeting T cells, with two distinct antigen-recognition domains targeting two tumor antigens. (C) Physiological CAR: CAR structure comprising a ligand and receptor molecule, rather than $\mathrm{scFv}$, to recognize the paired molecule on the tumor cell. (D) Universal CAR: Extracellular domain expresses the avidin-biotin labeled mAb, instead of scFv, which can recognize almost all target antigens specific to mAb. (E) I-CAR: CTLA-4 and PD-1 are two inhibitor receptors that can reversibly regulate the signaling of TCR and can enhance the function of chimeric receptors. CTLA-4 or PD-1 are intracellular domains in I-CARs, which trigger inhibitory signals on $\mathrm{T}$ cells, such as a reduction of target cell lytic action and cytokine production. The most important factor of I-CAR-T is its ability to distinguish normal and abnormal antigens on target cancer cells. CAR, chimeric antigen receptor; scFv, single-chain variable fragment; mAb, monoclonal antibody; PD-1, programmed death 1; CTLA-4, cytotoxic T lymphocyte-associated protein 4; I-CAR, inhibitory CAR; TM, transmembrane.

Tandem CARs (Tan-CARs). Conventional CARs cannot meet higher expectations under certain circumstances, such as the downregulation or alteration of targeted antigens that can occur in cancerous cells. These conditions subsequently lead to antigenic loss or escape variations (60). To overcome this shortcoming, scientists are attempting to develop advanced technology, in which two particular antigen recognition sites are joined by a linker, placed in tandem on a single intracellular domain and expressed as a single CAR on a cell surface, termed a Tan-CAR. This model enables the synchronized targeting of both antigens on a single cancer cell or tumor microenvironment. In this manner, it enhances the activation and stimulation of $\mathrm{T}$ cells by increasing their avidity and expanding their therapeutic properties (61). Tan-CARs have several significant curative implications as they are as potent as standard disease models with single antigen-specific CARs. Additionally, they are more efficient and less noxious in a higher disease load setting (62). This may be attributed to optimized cytokine production and limited cell killing, as evident from preclinical studies on Tan-CAR T cells in a mouse tumor model, which confirmed its possibility for remedial implication in human disease consisting of B-cell antigen CD19 and human epidermal growth factor receptor 2 (HER2) (63).
Recently, a trivalent CAR T cell was designed by a group of scientists by simultaneously co-targeting multiple antigens, such as HER2, IL-13 receptor $\alpha 2$ and ephrin A2, to overcome interpatient changeability with a propensity to target almost $100 \%$ of tumor cells (64).

Inhibitory CARs (I-CARs). It has been reported that certain novel immunoinhibitory receptors are involved in $\mathrm{T}$ cell activation and the attenuation or termination of $\mathrm{T}$ cell responses, such as programmed death-1 (PD-1), programmed death-ligand 1 (PD-L1) and cytotoxic T-lymphocyte-associated antigen 4 (CTLA-4). These pathways are regarded as cancer immunotherapy breakthroughs (65). Recently, two immunologists won the Novel Prize in Physiology/Medicine, Dr James Allison and Dr Tasuku Honjo, for their profound discovery in the field of cancer immunotherapy. Dr Allison's work focused on the $\mathrm{T}$ cell surface protein CTLA-4; he found that the inhibition of immune cells and antibodies against CTL-4 eliminated malignant growth and prevented new tumor formation (66). This finding was tested on 14 patients with metastatic melanoma, with relapse observed in three patients. In 2011, the FDA approved an anti-CTLA-4 (ipilimumab) antibody as a treatment for high-grade melanoma (67). 
Similarly, Dr Honjo's team investigated a novel T cell protein, PD-1, which was discovered in 1992 (68). They observed that PD-L1 presenting on healthy cells and malignant cells bind to PD-1. They reported another similar molecule, PD-L2, that also binds to PD-1. Based on these findings, they published a report that malignant cells produced PD-L1 and blocked PD-L1 using a counteracting antigen to inhibit tumor growth (69). The first clinical trials to target malignancy were launched in 2006, which indicated significant viability in a number of patients in 2012. The FDA approved the main PD-1 checkpoint inhibitors, nivolumab and pembrolizumab (70,71), for treating melanoma in 2014 (72). However, a single treatment may not be sufficient, which is the reason that a consolidated treatment targeting CTLA-4 and PD-1 is currently being investigated. Both Dr Allison and Dr Honjo encouraged the merging of various strategies to generate more advanced forms of the drug for the immune system to inhibit tumor cells more effectively (73).

Certain tumor cells contain a high level of PD-L1, which assists in evading immune attack. It has already been investigated that PD-1- or CTLA-4-based I-CARs can efficiently control the cytotoxicity, secretion of cytokines, and proliferation and cytotoxicity stimulated by endogenous TCR or an activating chimeric receptor (74). I-CARs are designed to control the actions of CAR T cells through inhibitory receptors. This advanced feature unites the action of two chimeric receptors; one of these generates a dominant-negative signal that restricts the responses of activated CAR T cells by the activating receptor. I-CARs can inhibit the activator CAR response to antigens expressed only by normal cells, thus differentiating between cancer and normal cells (75). Therefore, using genetic engineering to inhibit $\mathrm{T}$ cell inhibition physiology and regulate $\mathrm{T}$ cell response can be harnessed in an antigen-selective manner. This has been experimentally confirmed preclinically in a mouse model by designing an I-CAR using surface antigen recognition domains CTLA-4 and PD-1. In mice lacking CTLA-4 receptor, substantial T cell activation and proliferation were observed, ultimately leading to rigorous systemic autoimmune disease (76). Similarly, PD-1 is another the inhibitory receptor, which was found to be particularly expressed by activated $\mathrm{T}$ cells causing glomerulonephritis and arthritis in C57BL/6 mice and certain non-obese diabetic mice affected by insulitis (77).

Physiological CARs. Initially, several CAR constructions contained $\mathrm{ScFV}$ of murine origin. This is associated with the risk of an immune response to the modified cells, and the resulting anaphylaxis of CAR T cell transfer cannot be avoided. These disadvantages limit the persistence of the infused cells. Therefore, besides conventional CAR, a physiological CAR has been developed, also known as a receptor-ligand CAR, which can recognize and bind to tumor antigens, such as HER3 and HER4 (78). The physiological CAR consists of an antigen receptor and a $\mathrm{CD} 3 \zeta$ intracellular signaling domain with or without a transmembrane region, which can also be engineered into immune cells to target the ligands expressed on tumor cells. This approach increases the capability of $\mathrm{T}$ lymphocytes to distinguish tumor-related targets and eliminate cancer cells (79). This physiological CAR is an emerging field of CAR T cell therapy with limited published reports.
Experimental trials may have been initiated but the outcomes have not yet been published.

UniversalCARs $(u C A R s)$.Although scFv is specifically directed against tumor-associated antigens, the recognition specificity potential of CAR T cells is inadequate. Therefore, uCARs were developed to overcome this limitation. To construct a universal CAR, biotin or anti-fluorescein isothiocyanate (FITC) scFv is used as a targeting region, which is fused to a transmembrane domain with one or two endodomains (80). The uCAR-expressing $\mathrm{T}$ cells can efficiently recognize and remove cancer cells through the binding of FITC-labeled or biotinylated antigen-specific mAbs, which, in turn, activate the $\mathrm{T}$ cells and stimulate their proliferation and production of cytokines (81). The mSA2 CAR T cell is a uCAR, which can be fused to a biotinylated tumor-specific antibody to specifically target various types of tumor. As with interferon $\gamma$, it is well equipped for interceding malignant cell lysis and cytokine production (82). Human clinical trials involving uCAR T cells are ongoing. Two children with relapsed and refractory B-ALL achieved molecular and cytogenic remission following uCAR T therapy. Clinical trials have been initiated on uCAR T cell therapy specific to CD19-positive cells (NCT03166878 and NCT03229876). However, detailed information and conclusions are not yet available (83).

Natural killer (NK)-CARs. NK cells are a type of cytotoxic $\mathrm{T}$ cell that are essential for natural immunity. The function of NK cells is similar to that of cytotoxic T cells in the adaptive immune response of vertebrates. Immune cells generally identify MHC complexes expressed on infectious cell surfaces to elicit cytokine production, thus generating an immune response, culminating in the apoptosis or death of infectious cells (84). NK cells are the only immune cells that identify infected cells in the absence of MHC and antibodies, thus eliciting a rapid immune response. These are known as 'natural killers' as they do not require activation to destroy cells that are devoid of 'self' MHC class I molecule markers (85), making them important for destructive cells with missing MHC I markers.

Cancer cells that do not cause any inflammation are treated as self by the immune system and do not stimulate a $\mathrm{T}$ cell response. NK cells produce a number of cytokines, including tumor necrosis factor $\alpha$, interferon $\gamma$ and IL-10, which act as immune suppressors (86). The activation of NK cells leads to the gradual formation of cytolytic effectors cells, such as dendritic cells, macrophages and neutrophils, which consequently facilitate antigen-specific T and B cell responses. NK cell-mediated tumor cell lysis involves several receptors, including NKp44, NKp46, NKG2D, NKp30 and DNAM. Malignant cells usually express NKG2D in addition to ULBP and MICA $(87,88)$. The clinical effectiveness of CAR T cells has been shown for ALL; however, this therapeutic approach has not been confirmed for acute myeloid leukemia (AML), suggesting the need for other therapeutic options (89). Hypothetically, automotive NK cells have an additional favorable toxic effect in comparison to CAR T cells, particularly for avoiding unfavorable effects such as CRS. Additionally, in contrast to T cells, donor NK cells do not target non-hematopoietic cells, indicating that NK cell-mediated antitumor activity may be activated in the absence of graft-vs.-host disease (90) (Fig. 4). 


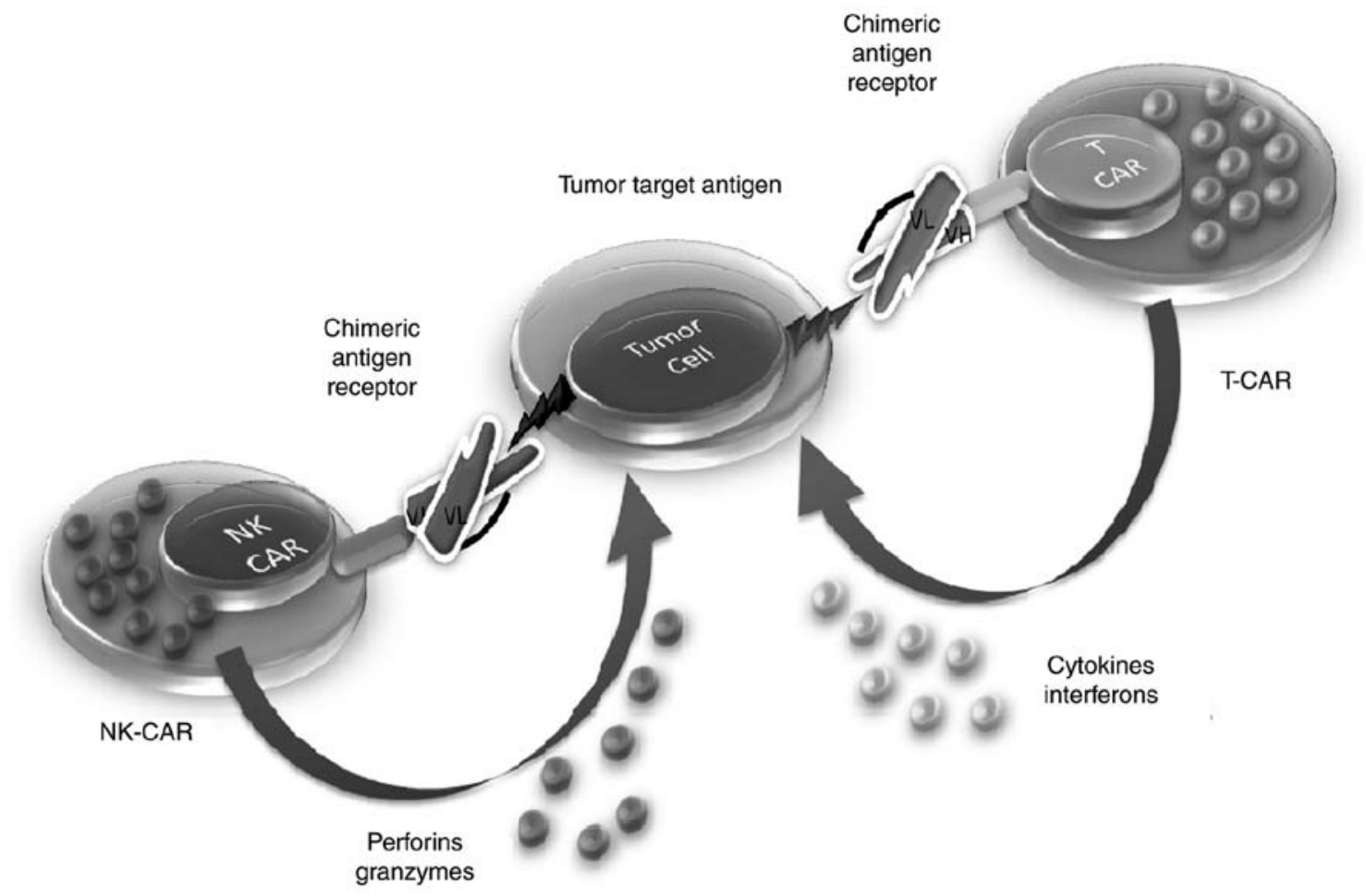

Figure 4. T cells and NK cells in the CAR platform. NK cells are fundamental components of the innate immune system and serve an essential role in host immunity against cancer. Currently, CAR-engineered NK cells are targeted to NKGD2, CD16 antigens; upon encounter with a tumor antigen on the cancer cell, the NK-CAR secretes perforins and granzymes, which directly mediate the cytotoxicity of the targeted tumor cell. CAR T cells secrete cytokines, such as interferons and TNF-a, which also mediate cell cytotoxicity and eventually cancer cell death. CAR, chimeric antigen receptor; NK, natural killer; NKGD2, natural killer group 2 member D.

CRISPR CARs. CRISPR is a gene modifying tool that uses a guide gRNA to modify a DNA sequence. As this technology is an integration-free gene incorporation system, it offers a foolproof and competent gene knock-in process. Following the significant progress associated with CRISPR technology, it has the potential to emerge as a promising immunotherapy (91). The CRISPR system can be directly applied to mammalian cells via transfection using a plasmid that contains both nuclease and sgRNA. Cas9 encodes a large molecule with a multifunctional DNA endonuclease and is known to excise dsDNA from 3-bp upstream of the protospacer adjacent motif (PAM) (92). Once the nuclease binds to its gRNA, the compound scans for an integral target DNA sequence (93). The PAM sequence has a significant role in recognizing self and non-self sequences. The local PAM sequence is usually used as a 'spy' on the nuclease sequence 5-NGG-3, in which $\mathrm{N}$ is any of the four deoxyribonucleic acid bases (94).

Recently published reports suggest that CRISPR technology can deliver the CAR gene to the TRAC locus of T cells. In this regard, CRISPR-edited universal-CAR T cell therapy has been used in humans (NCT03166878 and NCT03229876). This technology is rapidly developing with the potential for gene correction (82). It is reported that anti-CD19 CAR to the TCR $\alpha$ constant locus (TRAC locus) not only results in increased $\mathrm{T}$ cell potency but also in the consistent expression of CAR in peripheral blood T cells (95). CRISPR-modified cells have been shown to perform well in generally constructed CAR T cells in a mouse model of ALL (96). It has also been demonstrated that targeting the TRAC locus turns on CAR signaling, thereby initiating successful internalization and stimulation of the CAR for single and repeated exposure to a tumor antigen. It also delays effector $\mathrm{T}$ cell differentiation and exhaustion (97). Multiplex genome editing is another attractive application of the CRISPR/Cas9 tool. Proficient genomic disturbance of multiple gene loci to create a universal donor cell and a potent effector $\mathrm{T}$ lymphocyte targeted to different inhibitory pathways, such as PD-1 and CTLA4, is established by incorporating several gRNAs into a CAR vector. Furthermore, two-fold knockout of the TCR gene and HLA class I can effectively permit the generation of an allogeneic uCAR T cell, in addition to CAR T cells that are universally Fas-resistant via three-fold gene disruption (98).

\section{Advantages of CAR therapy over other therapies}

The most notable advantage of CAR T cell therapy over other cancer therapies is the abrupt time intervention and single infusion of CAR T cells. Additionally, 2-3 weeks of proper care and observation is sufficient for the patient. CAR T cell therapy is regarded as a 'drug of the present day' and its efficacy may persist for decades as the cells can survive in the host body in the long term, with a constant ability to find and destroy cancer cells during relapse $(2,3)$. Currently, CAR $T$ cell therapy is licensed for use in patients for whom transplantation has not been curative and who relapse following transplant. CAR T cell therapy is expected to be a substitute for different types of transplant (99). Clinical trials on blood cancer have shown that, even in patients with a refractory 
Table I. List of chimeric antigen receptor therapy clinical trials.

\begin{tabular}{lll}
\hline Target antigen & \multicolumn{1}{c}{ Type of cancer } & Clinical trial ID \\
\hline CD19 & BALL & NCT01044069 \\
CD19 & B-CLL & NCT00466531 \\
CD19 & Leukemia & NCT01416974 \\
CD19 & Lymphoma & NCT00586391 \\
CD19 & B-NHL/CLL & NCT00608270 \\
CD20 & Mantel cell leukemia/B-NHL & NCT00621452 \\
CD22 & Non-Hodgkins Lymphoma & NCT02315612 \\
CD19/CD20 & B-Non Hodgkins Lymphoma & NCT00621452 \\
CD19/CD22 & B-cell malignancy & NCT03185494 \\
CD133 & Hepatocellular carcinoma & NCT02541370 \\
CD171 & Neuroblastoma & NCT02311621 \\
PMSA & Prostate cancer & NCT001140373 \\
CEA & Breast cancer & NCT00673829 \\
CEA & Colorectal cancer & NCT00673827 \\
CEA & Lungs cancer & NCT00673322 \\
HER-2 & Lungs cancer & NCT00889954 \\
HER-2 & Osteosarcoma & NCT00902044 \\
HER-2 & Glioblastoma & NCT01109095 \\
CD30 & Lymphoma & NCT02274584 \\
FAP & Malignant pleural mesothelioma & NCT01722149 \\
NKGD2 & Leukemia & NCT02203825 \\
GD2 & Neuroblastoma, osteosarcoma & NCT03356795 \\
EGFRVIII & Glioblastoma & NCT02309373 \\
Mesothelin & Pancreatic cancer & NCT02706782 \\
CD38/CD123 & B-Cell Malignancies & NCT03125577 \\
ROR1 & Chronic lymphocytic leukemia & NCT02194374 \\
MUC16 & Ovarian carcinoma & NCT02498912 \\
GPC3 & Lung squamous cell carcinoma & NCT03198546 \\
VEGFRII & Renal cancer & NCT01218867 \\
\hline PMSA & a & \\
\hline
\end{tabular}

PMSA, prostate-specific membrane antigen; ROR1, receptor tyrosine kinase-like orphan receptor 1; NKGD2, natural killer group 2 member D, expressed in natural killer cells; GD2, disganglioside molecule expressed on tumors of neuroectodermal origin; EGFRVIII, epidermal growth factor receptor variant III; Mesothelin, differentiation antigen expressed on mesothelial cells and overexpressed in numerous human tumors; MUC16, also known as CA125, is a biomarker for ovarian cancer; GPC3, glypican 3, is a cell surface protein overexpressed in numerous solid tumors; VEGFRII, vascular endothelial growth factor receptor II.

condition in which cancer reverted following several transplants, CAR T cell therapy was successful in completely eradicating the disease (100). Additionally, with CAR T cells, patients can live life without the risk of relapse and benefit from a sanatory treatment, such as stem cell transplantation. Therefore, CAR T cell therapy can be referred to as a 'living drug' (101).

\section{CAR T cell therapy trials for solid tumors}

Several clinical trials are currently examining the use of CAR T cell therapy against solid tumors and other diseases. Reports suggest that mesothelin-specific CAR mRNA-engineered $\mathrm{T}$ cells can induce antitumor activity in solid malignancies $(102,103)$. Furthermore, CAR technology has been used in organ transplantation using two novel HLA-A2-specific
CARs, one representing a CD28-CD3d signaling domain (CAR) and the other missing an intracellular signaling domain (dCAR). The adoptive transfer of allospecific regulatory $\mathrm{T}$ cells (Tregs) provides a better safeguard from graft rejection compared with that of polyclonal Tregs (104). CAR comprising the ICOS signaling domain liaises with the effective antitumor effect on epidermal growth factor receptor variant III (EGFRvIII)-expressing glioma (105). The preclinical evaluation of CAR T cell therapy targeting the tumor antigen 5T4 in ovarian cancer has been associated with a successful outcome (106). An unexpected evolutionary finding was reported during the investigation of CAR targeting autoimmune diseases; therapy lacking autoimmune diseases that purposely target only the disease-causing cells, chimeric autoantibody receptor (CAAR), contain pemphigus vulgaris autoantigen, desmoglein (Dsg3), combined to CD137-CD3d signaling 
domains. Dsg3 CAAR-T cells exhibit accurate toxicity against anti-Dsg3-expressing cells (107). Certain solid tumor CAR targets are undergoing research with varied genetic products arising from gene mutations (EGFRvIII) (108) or modified glycosylation patterns (MUC1) (109), and cancer-testis antigen-derived peptides (MAGE), CAR specifically targets certain overexpressed antigens in breast cancer, lung cancer and pancreatic cancer, such as carcinoembryonic antigen (110) GD2, prostate-specific membrane antigen, HER2/ERBB2, MUC16 (111) and mesothelin or tumor-affiliated stoma (fibroblast activation protein and vascular endothelial growth factor receptor) (112).

\section{Success rates of approved therapies}

As per the 2018 records on the total clinical trials conducted in the immuno-oncology domain, 220 trials involving CAR $\mathrm{T}$ therapy were performed to identify specific targets. Successfully developed CAR T cell drugs that are available to the market include CTL019 (Kymriah) (113), KTE-C19 (Yescarta) (114) and JCAR015 (115). These have been developed by companies known to be antecedents of CAR $\mathrm{T}$ cell therapy development, such as Novartis in association with the University of Pennsylvania, Kite Pharma with National Cancer Institute, and Juno Therapeutics with Sloan Kettering, respectively, and are used to treat ALL, NHL and ALL. These CAR T therapies represent a defining moment in 2017 in the field of oncology. The first two therapies specific to CD19 and approved by the FDA included Kymriah (tisagenlecleucel-T) and Yescarta (axicabtageneciloleucel) by Novartis and Kite Pharma/Gilead Sciences, respectively (116).

The global ELIANA trial reported a high success rate, with a 3 -month complete remission rate of $83 \%$ with tisagenlecleucel, and a 6-month survival rate of $89 \%$ (117). Another trial, ZUMA-1, reported an equivalent results with an $82 \%$ overall response rate and $54 \%$ of complete remission rate following a single infusion of the therapeutic regime in 8 months. This indicates that the remission rate was more pronounced in pediatric B-ALL than that in adult relapsed/refractory DLBCL; however, reactivity was high in both diseases (118).

Furthermore, multiple clinical investigations have been implemented by Cellectis following UCART19. Cellectis is currently leading with two successful FDA Investigational New Drug (IND)-approved allogeneic CAR T approaches (119): UCART123 for patients with blastic plasmacytoid dendritic cell neoplasm and AML (120) and UCART22 IND for patients with B-ALL (121). Two other ongoing clinical trials are UCARTCS1 for suppressing CS1-expressing hematologic malignancies (122) and UCART38 for CD38-expressing hematologic malignancies. UCART38 is specifically developed to target T cell ALL, multiple myeloma, mantle cell lymphoma and NHL $(123,124)$. A list of CAR therapy clinical trials are listed in Table I.

\section{Future prospects}

Although immunotherapy has achieved clinical success in treating blood cancer, the same success rates have not been observed for solid tumors. The various challenges associated with its safety, cost-effectiveness and quality require thorough investigation in order to implement this therapy for all cancer types. Another approach is to integrate CAR T cells with different types of immunotherapy to enhance its effectiveness. For example, CARs may be combined with certain checkpoint inhibitors, which limit tumor defense mechanisms against $\mathrm{T}$ cells. It is expected that future CAR T cell therapy regimens will target several diverse molecules for a particular type of tumor, such that CAR T cells can efficiently recognize cancerous cells even if these undergo mutations in their target molecules.

A number of CAR T therapies are already available to the market, but these are expensive, for example, $\$ 475,000$ $(€ 400,000)$ for Yescarta and $\$ 373,000(€ 316,000)$ for Kymriah. According to experts, when hospitalization expenses and the costs of other drugs required for the treatment are also considered, the cost increases to almost $\$ 1,500,000$ per cancer patient. Therefore, a possible solution is to reduce the cost of allogeneic CAR T treatment by supplying $\mathrm{T}$ lymphocytes from a healthy individual that can be readily utilized when a patient requires it, rather than genetically modifying each patient's T cells individually. Considerable scientific challenges also exist with regard to immunology, in addition to manufacturing, transportation and banking solutions to enhance the extensive treatment of patients. Therefore, scientists are investigating measures to overcome clinical challenges in terms of regulations. CAR $\mathrm{T}$ cells are available in several scientific frameworks, which may vary widely in different countries. These combined challenges and technology require standardization; however, CAR T cells offer patients hope of advanced treatment. As the first therapy is already available in the market, there is potential for a specific and improved alternative becoming available in upcoming decades.

\section{Acknowledgements}

We acknowledge the Science and Engineering Research Board for the generous funding.

\section{Funding}

Funding from the Science and Engineering Board, Department of Science and Technology, Government of India is duly acknowledged. ECR/2016/000584.

\section{Availability of data and materials}

Not applicable.

\section{Authors' contributions}

RM and NG conceptualized and co-wrote the manuscript. CRC, SA, PS and PG contributed to the literature review, organization and writing of various sections of the manuscript. NG is the PI and grant holder.

\section{Ethical approval and consent to participate}

Not applicable. 


\section{Patient consent for publication}

Not applicable.

\section{Competing interests}

The authors declare that they have no competing interests.

\section{References}

1. Restifo NP, Dudley ME and Rosenberg SA: Adoptive immunotherapy for cancer: Harnessing the T cell response. Nat Rev Immunol 12: 269-281, 2012.

2. Galluzzi L and Martin P: CARs on a highway with roadblocks. Oncoimmunology 6: e1388486, 2017.

3. Perales MA, Kebriaei P, Kean LS and Sadelain M: Building a safer and faster CAR: Seatbelts, airbags, and CRISPR. Biol Blood Marrow Transplant 24: 27-31, 2018.

4. Sharpe M and Mount N: Genetically modified T cells in cancer therapy: Opportunities and challenges. Dis Model Mech 8: 337-350, 2015

5. McGuirk J, Waller EK, Qayed M, Abhyankar S, Ericson S, Holman P, Keir C and Myers GD: Building blocks for institutional preparation of CTL019 delivery. Cytotherapy 19: 1015-1024, 2017.

6. Prasad V: Immunotherapy: Tisagenlecleucel-the first approved CAR-T-cell therapy: Implications for payers and policy makers. Nat Rev Clin Oncol 15: 11-12, 2018.

7. Neelapu SS, Tummala S, Kebriaei P, Wierda W, Gutierrez C, Locke FL, Komanduri KV, Lin Y, Jain N, Daver N, et al: Chimeric antigen receptor T-cell therapy-assessment and management of toxicities. Nat Rev Clin Oncol 15: 47-62, 2018.

8. Miliotou AN and Papadopoulou LC: CAR T-cell therapy: A new era in cancer immunotherapy. Curr Pharm Biotechnol 19: 5-18, 2018.

9. Mirzaei HR, Jamali A, Jafarzadeh L, Masoumi E, Alishah K, Fallah Mehrjardi K, Emami SAH, Noorbakhsh F, Till BG and Hadjati J: Construction and functional characterization of a fully human anti-CD19 chimeric antigen receptor (huCAR)-expressing primary human T cells. J Cell Physiol 234: 9207-9215, 2019.

10. Vormittag P, Gunn R, Ghorashian S and Veraitch FS: A guide to manufacturing CAR T cell therapies. Curr Opin Biotechnol 53: 164-181, 2018.

11. Abate-Daga D and Davila ML: CAR models: Next-generation CAR modifications for enhanced T-cell function. Mol Ther Oncolytics 3: 16014, 2016.

12. Yang QY, Yang JD and Wang YS: Current strategies to improve the safety of chimeric antigen receptor (CAR) modified T cells. Immunol Lett 190: 201-205, 2017.

13. Mirzaei HR, Mirzaei H, Namdar A, Rahmati M, Till BG and Hadjati J: Predictive and therapeutic biomarkers in chimeric antigen receptor T-cell therapy: A clinical perspective. J Cell Physiol 234: 5827-5841, 2019.

14. Dai H, Wang Y, Lu X and Han W: Chimeric antigen receptors modified T-cells for cancer therapy. J Natl Cancer Inst 108: pii: $\operatorname{djv} 439,2016$

15. Mirzaei HR, Mirzaei H, Lee SY, Hadjati J and Till BG: Prospects for chimeric antigen receptor (CAR) $\gamma \delta$ T cells: A potential game changer for adoptive T cell cancer immunotherapy. Cancer Lett 380: 413-423, 2016.

16. Morgan RA: Chapter 17-Adoptive T-cell therapy: Engineering T-cell receptors. Cancer Immunother (Sec Ed): 261-272, 2013.

17. Louis CU, Savoldo B, Dotti G, Pule M, Yvon E, Myers GD, Rossig C, Russell HV, Diouf O, Liu E, et al: Antitumor activity and long-term fate of chimeric antigen receptor-positive $\mathrm{T}$ cells in patients with neuroblastoma. Blood 118: 6050-6056, 2011.

18. Duong CP, Yong CS, Kershaw MH, Slaney CY and Darcy PK: Cancer immunotherapy utilizing gene-modified T cells: From the bench to the clinic. Mol Immunol 67: 46-57, 2015.

19. Sadelain M: CAR therapy: The CD19 paradigm. J Clin Invest 125: 3392-3400, 2015.

20. Eshhar Z: The T-body approach: Redirecting T cells with antibody specificity. Handb Exp Pharmacol: 329-342, 2008.

21. Brentjens R, Yeh R, Bernal Y, Riviere I and Sadelain M: Treatment of chronic lymphocytic leukemia with genetically targeted autologous T cells: Case report of an unforeseen adverse event in a phase I clinical trial. Mol Ther 18: 666-668, 2010.
22. Till BG, Jensen MC, Wang J, Qian X, Gopal AK, Maloney DG, Lindgren CG, Lin Y, Pagel JM, Budde LE, et al: CD20-specific adoptive immunotherapy for lymphoma using a chimeric antigen receptor with both CD28 and 4-1BB domains: Pilot clinical trial results. Blood 119: 3940-3950, 2012.

23. Park JH and Brentjens RJ: Are all chimeric antigen receptors created equal? J Clin Oncol 33: 651-653, 2015.

24. Qian L, Li D, Ma L, He T, Qi F, Shen J and Lu XA: The novel anti-CD19 chimeric antigen receptors with humanized $\mathrm{scFv}$ (single-chain variable fragment) trigger leukemia cell killing. Cell Immunol 304-305: 49-54, 2016.

25. Lock D, Mockel-Tenbrinck N, Drechsel K, Barth C, Mauer D, Schaser T, Kolbe C, Al Rawashdeh W, Brauner J, Hardt O, et al: Automated manufacturing of potent CD20-directed chimeric antigen receptor $\mathrm{T}$ cells for clinical use. Hum Gene Ther 28: 914-925, 2017.

26. Tang XY, Sun Y, Zhang A, Hu GL, Cao W, Wang DH, Zhang B and Chen H: Third-generation CD28/4-1BB chimeric antigen receptor $\mathrm{T}$ cells for chemotherapy relapsed or refractory acute lymphoblastic leukaemia: A non-randomised, open-label phase I trial protocol. BMJ Open 6: e013904, 2016.

27. Yeku OO and Brentjens RJ: Armored CAR T-cells: Utilizing cytokines and pro-inflammatory ligands to enhance CAR T-cell anti-tumour efficacy. Biochem Soc Trans 44: 412-418, 2016.

28. Chmielewski M and Abken H: TRUCKs: The fourth generation of CARs. Expert Opin Biol Ther 15: 1145-1154, 2015.

29. Kueberuwa G, Kalaitsidou M, Cheadle E, Hawkins RE and Gilham DE: CD19 CAR T cells expressing IL-12 eradicate lymphoma in fully lymphoreplete mice through induction of host immunity. Mol Ther Oncolytics 8: 41-51, 2017.

30. Kerkar SP, Muranski P, Kaiser A, Boni A, Sanchez-Perez L, Yu Z, Palmer DC, Reger RN, Borman ZA, Zhang L, et al: Tumor-specific CD8+ T cells expressing interleukin-12 eradicate established cancers in lymphodepleted hosts. Cancer Res 70: 6725-6734, 2010

31. Giacca $\mathrm{M}$ and Zacchigna S: Virus-mediated gene delivery for human gene therapy. J Control Release 161: 377-388, 2012.

32. Yi Y, Noh MJ and Lee KH: Current Advances in retroviral gene therapy. Curr Gene Ther 11: 218-228, 2011.

33. Kidd ME, Shin S and Shea LD: Fibrin hydrogels for lentiviral gene delivery in vitro and in vivo. J Control Release 157: 80-85, 2012.

34. Munñoz-López M and García-Perez JL: DNA transposons: Nature and applications in genomics. Curr Genomics 11: 115-128, 2010.

35. Morita D, Nishio N, Saito S, Tanaka M, Kawashima N, Okuno Y, Suzuki S, Matsuda K, Maeda Y, Wilson MH, et al: Enhanced expression of Anti-CD19 chimeric antigen receptor in piggyBac transposon-engineered T cells. Mol Ther Methods Clin Dev 8: 131-140, 2017.

36. Kebriaei P, Singh H, Huls MH, Figliola MJ, Bassett R, Olivares $S$, Jena B, Dawson MJ, Kumaresan PR, Su S, et al: Phase I trials using sleeping beauty to generate CD19-specific CAR T cells. J Clin Invest 126: 3363-3376, 2016.

37. Manuri PV, Wilson MH, Maiti SN, Mi T, Singh H, Olivares S, Dawson MJ, Huls H, Lee DA, Rao PH, et al: piggyBac Transposon/Transposase system to generate CD19-specific T cells for the treatment of B-lineage malignancies. Hum Gene Ther 21: 427-437, 2010.

38. Yarmush ML, Golberg A, Serša G, Kotnik T and Miklavčič D: Electroporation-based technologies for medicine: Principles, applications, and challenges. Annu Rev Biomed Eng 16: 295-320, 2014.

39. Chicaybam L, Sodre AL, Curzio BA and Bonamino MH: An efficient low cost method for gene transfer to $\mathrm{T}$ lymphocytes. PLoS One 8: e60298, 2013.

40. Chicaybam L, Barcelos C, Peixoto B, Carneiro M, Limia CG, Redondo P, Lira C, Paraguassú-Braga F, Vasconcelos ZF, Barros L and Bonamino MH: An efficient electroporation protocol for the genetic modification of mammalian cells. Front Bioeng Biotechnol 4: 99, 2017.

41. Kotnik T, Frey W, Sack M, Haberl Meglič S, Peterka M and Miklavčič D: Electroporation-based applications in biotechnology. Trends Biotechnol 33: 480-488, 2015.

42. Ramamoorth $M$ and Narvekar A: Non viral vectors in gene therapy-an overview. J Clin Diagn Res 9: GE01-GE06, 2015.

43. Yin H, Kauffman KJ and Anderson DG: Delivery technologies for genome editing. Nat Rev Drug Discov 16: 387-399, 2017.

44. Smith TT, Stephan SB, Moffett HF, McKnight LE, Ji W, Reiman D, Bonagofski E, Wohlfahrt ME, Pillai SPS and Stephan MT: In situ programming of leukaemia-specific T cells using synthetic DNA nanocarriers. Nat Nanotechnol 12: 813-820, 2017. 
45. Miller MA: Nanoparticles improve economic mileage for CARs Sci Transl Med 9: pii: eaan2784, 2017.

46. Smith TT, Moffett HF, Stephan SB, Opel CF, Dumigan AG, Jiang X, Pillarisetty VG, Pillai SPS, Wittrup KD and Stephan MT: Biopolymers codelivering engineered T cells and STING agonists can eliminate heterogeneous tumors. J Clin Invest 127: 2176-2191, 2017.

47. Dowaidar M, Abdelhamid HN, Hällbrink M, Freimann K, Kurrikoff K,Zou X and Langel Ü: Magnetic nanoparticle assisted Self-assembly of cell penetrating peptides-oligonucleotides complexes for gene delivery. Sci Rep 7: 9159, 2017.

48. Kebriaei P: CAR T-cell therapies: Overcoming the challenges and new strategies. Clin Lymphoma Myeloma Leuk 17 (Suppl 2): S74-S78, 2017.

49. Bonifant CL, Jackson HJ, Brentjens RJ and Curran KJ: Toxicity and management in CAR T-cell therapy. Mol Ther Oncolytics 3 : $16011,2016$.

50. Brudno JN and Kochenderfer JN: Toxicities of chimeric antigen receptor T cells: Recognition and management. Blood 127: 3321-3330, 2016.

51. Neelapu SS, Locke FL, Bartlett NL, Lekakis LJ, Miklos DB, Jacobson CA, Braunschweig I, Oluwole OO, Siddiqi T, Lin Y, et al: Axicabtagene Ciloleucel CAR T-cell therapy in refractory large B-cell lymphoma. N Engl J Med 377: 2531-2544, 2017.

52. Paietta E: Immunobiology of acute leukemia. In: Neoplastic diseases of the blood. Springer, Cham, pp237-279, 2018.

53. Zah E, Lin MY, Jensen MC, Silva-Benedict A and Chen YY: Abstract IA12: Combating antigen escape with CD19/CD20 bispecific CAR-T cell therapy. Cancer Immunol Res 5 (3 Suppl): IA12, 2017

54. Majzner RG and Mackall CL: Tumor antigen escape from CAR T-cell therapy. Cancer Discov 8: 1219-1226, 2018.

55. Zhu M, Wu B, Brandl C, Johnson J, Wolf A, Chow A and Doshi S Blinatumomab, a Bispecific T-cell Engager (BiTE(®)) for CD-19 targeted cancer immunotherapy: Clinical pharmacology and its implications. Clin Pharmacokinet 55: 1271-1288, 2016.

56. Martyniszyn A, Krahl AC, André MC, Hombach AA and Abken H: CD20-CD19 Bispecific CAR T cells for the treatment of B-cell malignancies. Hum Gene Ther 28: 1147-1157, 2017.

57. Zhu F, Shah N, Xu H, Schneider D, Orentas R, Dropulic B, Hari P and Keever-Taylor CA: Closed-system manufacturing of CD19 and dual-targeted CD20/19 chimeric antigen receptor $\mathrm{T}$ cells using the CliniMACS prodigy device at an academic medical center. Cytotherapy 20: 394-406, 2018.

58. Sun LL, Ellerman D, Mathieu M, Hristopoulos M, Chen X, Li Y, Yan X, Clark R, Reyes A, Stefanich E, et al: Anti-CD20/CD3 $\mathrm{T}$ cell-dependent bispecific antibody for the treatment of B cell malignancies. Sci Transl Med 7: 287ra70, 2015

59. Zhang W, Liu Y, Wang Y, Wang C, Yang QM, Zhu HL and Han WD: Long-term safety and efficacy of CART-20 cells in patients with refractory or relapsed B-cell non-Hodgkin lymphoma: 5-years follow-up results of the phase I and IIa trials. Signal Transduct Target Ther 2: 17054, 2017.

60. Hegde M, Mukherjee M, Grada Z, Pignata A, Landi D, Navai SA Wakefield A, Fousek K, Bielamowicz K, Chow KK, et al: Tandem CAR T cells targeting HER2 and IL13R $\alpha 2$ mitigate tumor antigen escape. J Clin Invest 126: 3036-3052, 2016.

61. Schneider D, Xiong Y, Wu D, Nölle V, Schmitz S, Haso W, Kaiser A, Dropulic B and Orentas RJ: A tandem CD19/CD20 CAR lentiviral vector drives on-target and off-target antigen modulation in leukemia cell lines. J Immunother Cancer 5: 42, 2017.

62. Grada Z, Hegde M, Byrd T, Shaffer DR, Ghazi A, Brawley VS, Corder A, Schönfeld K, Koch J, Dotti G, et al: TanCAR: A novel bispecific chimeric antigen receptor for cancer immunotherapy. Mol Ther Nucleic Acids 2: e105, 2013.

63. Ahmed N, Brawley V, Hegde M, Bielamowicz K, Kalra M, Landi D, Robertson C, Gray TL, Diouf O, Wakefield A, et al: HER2-specific chimeric antigen receptor-modified virus-specific $\mathrm{T}$ cells for progressive glioblastoma: A phase 1 dose-escalation trial. JAMA Oncol 3: 1094-1101, 2017.

64. Bielamowicz K, Fousek K, Byrd TT, Samaha H, Mukherjee M, Aware N, Wu MF, Orange JS, Sumazin P, Man TK, et al: Trivalent CAR T cells overcome interpatient antigenic variability in glioblastoma. Neuro Oncol 20: 506-518, 2018.

65. Ott PA, Hodi FS and Robert C: CTLA-4 and PD-1/PD-L1 blockade: New immunotherapeutic modalities with durable clinical benefit in melanoma patients. Clin Cancer Res 19: 5300-5309, 2013.
66. Curran MA, Montalvo W, Yagita H and Allison JP: PD-1 and CTLA-4 combination blockade expands infiltrating T cells and reduces regulatory $\mathrm{T}$ and myeloid cells within B16 melanoma tumors. Proc Natl Acad Sci USA 107: 4275-4280, 2010.

67. Hodi FS, O'Day SJ, McDermott DF, Weber RW, Sosman JA, Haanen JB, Gonzalez R, Robert C, Schadendorf D, Hassel JC, et al: Improved Survival with Ipilimumab in Patients with Metastatic Melanoma. N Engl J Med 363: 711-723, 2010

68. Iwai Y, Ishida M, Tanaka Y, Okazaki T, Honjo T and Minato N: Involvement of PD-L1 on tumor cells in the escape from host immune system and tumor immunotherapy by PD-L1 blockade. Proc Natl Acad Sci USA 99: 12293-12297, 2002.

69. Iwai Y, Hamanishi J, Chamoto K and Honjo T: Cancer immunotherapies targeting the PD-1 signaling pathway. J Biomed Sci 24: 26, 2017.

70. Ansell SM, Lesokhin AM, Borrello I, Halwani A, Scott EC, Gutierrez M, Schuster SJ, Millenson MM, Cattry D, Freeman GJ, et al: PD-1 Blockade with Nivolumab in relapsed or refractory Hodgkin's lymphoma. N Engl J Med 372: 311-319, 2015.

71. Chen R, Zinzani PL, Fanale MA, Armand P, Johnson NA, Brice P, Radford J, Ribrag V, Molin D, Vassilakopoulos TP, et al: Phase II study of the efficacy and safety of pembrolizumab for relapsed/refractory classic Hodgkin lymphoma. J Clin Oncol 35: 2125-2132, 2017.

72. Barbee MS, Ogunniyi A, Horvat TZ and Dang TO: Current status and future directions of the immune checkpoint inhibitors ipilimumab, pembrolizumab, and nivolumab in oncology. Ann Pharmacother 49: 907-937, 2015.

73. Curran MA, Kim M, Montalvo W, Al-Shamkhani A and Allison JP: Combination CTLA-4 blockade and 4-1BB activation enhances tumor rejection by increasing T-cell infiltration, proliferation, and cytokine production. PLoS One 6: e19499, 2011.

74. Seidel JA, Otsuka A and Kabashima K: Anti-PD-1 and Anti-CTLA-4 therapies in cancer: Mechanisms of action, efficacy, and limitations. Front Oncol 8: 86, 2018.

75. Ren J, Liu X, Fang C, Jiang S, June CH and Zhao Y: Multiplex genome editing to generate universal CAR T cells resistant to PD1 inhibition. Clin Cancer Res 23: 2255-2266, 2017.

76. Azijli K, Stelloo E, Peters GJ and Van Den Eertwegh AJ: New developments in the treatment of metastatic melanoma: Immune checkpoint inhibitors and targeted therapies. Anticancer Res 34: 1493-1505, 2014.

77. Deng L, Liang H, Burnette B, Beckett M, Darga T, Weichselbaum RR and Fu YX: Irradiation and anti-PD-L1 treatment synergistically promote antitumor immunity in mice. J Clin Invest 124: 687-695, 2014.

78. Shi H, Sun M, Liu L and Wang Z: Chimeric antigen receptor for adoptive immunotherapy of cancer: Latest research and future prospects. Mol Cancer 13: 219, 2014.

79. Liu L, Sun M and Wang Z: Adoptive T-cell therapy of B-cell malignancies: Conventional and physiological chimeric antigen receptors. Cancer Lett 316: 1-5, 2012.

80. Minutolo NG, Hollander EE and Powell DJ Jr: The emergence of universal immune receptor $\mathrm{T}$ cell therapy for cancer. Front Oncol 9: 176, 2019

81. Zhao J, Lin Q, Song Y and Liu D: Universal CARs, universal $\mathrm{T}$ cells, and universal CAR T cells. J Hematol Oncol 11: 132, 2018.

82. Lohmueller JJ, Ham JD, Kvorjak M and Finn OJ: mSA2 affinity-enhanced biotin-binding CAR T cells for universal tumor targeting. Oncoimmunology 7: e1368604, 2018.

83. Qasim W, Zhan H, Samarasinghe S, Adams S, Amrolia P, Stafford S, Butler K, Rivat C, Wright G, Somana K, et al: Molecular remission of infant B-ALL after infusion of universal TALEN gene-edited CAR T cells. Sci Transl Med 9: eaaj2013, 2017.

84. Glienke W, Esser R, Priesner C, Suerth JD, Schambach A, Wels WS, Grez M, Kloess S, Arseniev L and Koehl U: Advantages and applications of CAR-expressing natural killer cells. Front Pharmacol 6: 21, 2015.

85. Klingemann $\mathrm{H}$ : Are natural killer cells superior CAR drivers? Oncoimmunology 3: e28147, 2014.

86.Jiang H, Zhang W, Shang P, Zhang H, Fu W, Ye F, Zeng T, Huang H, Zhang X, Sun W, et al: Transfection of chimeric anti-CD138 gene enhances natural killer cell activation and killing of multiple myeloma cells. Mol Oncol 8: 297-310, 2014 . 
87. Boissel L, Betancur-Boissel M,Lu W, Krause DS, Van Etten RA, Wels WS and Klingemann H: Retargeting NK-92 cells by means of CD19- and CD20-specific chimeric antigen receptors compares favorably with antibody-dependent cellular cytotoxicity. Oncoimmunology 2: e26527, 2013.

88. Romanski A, Uherek C, Bug G, Seifried E, Klingemann H, Wels WS, Ottmann OG and Tonn T: CD19-CAR engineered NK-92 cells are sufficient to overcome NK cell resistance in B-cell malignancies. J Cell Mol Med 20: 1287-1294, 2016.

89. Hermanson DL and Kaufman DS: Utilizing chimeric antigen receptors to direct natural killer cell activity. Front Immunol 6: $195,2015$.

90. Tang X, Yang L, Li Z, Nalin AP, Dai H, Xu T, Yin J, You F, Zhu M, Shen W, et al: First-in-man clinical trial of CAR NK-92 cells: safety test of CD33-CAR NK-92 cells in patients with relapsed and refractory acute myeloid leukemia. Am J Cancer Res 8: 1083-1089, 2018.

91. Hsu PD, Lander ES and Zhang F: Development and Applications of CRISPR-Cas9 for genome engineering. Cell 157: 1262-1278, 2014.

92. Haurwitz RE, Jinek M, Wiedenheft B, Zhou K and Doudna JA: Sequence- and Structure-specific RNA processing by a CRISPR endonuclease. Science 329: 1355-1358, 2010.

93. Cox DB, Platt RJ and Zhang F: Therapeutic genome editing: Prospects and challenges. Nat Med 21: 121-131, 2015.

94. Shang W, Wang F, Fan G and Wang H: Key elements for designing and performing a CRISPR/Cas9-based genetic screen. J Genet Genomics 44: 439-449, 2017.

95. Mirzaei HR, Pourghadamyari H, Rahmati M, Mohammadi A, Nahand JS, Rezaei A and Hadjati J: Gene-knocked out chimeric antigen receptor (CAR) T cells: Tuning up for the next generation cancer immunotherapy. Cancer Lett 423: 95-104, 2018.

96. Eyquem J, Mansilla-Soto J, Giavridis T, van der Stegen SJ, Hamieh M, Cunanan KM, Odak A, Gönen M and Sadelain M: Targeting a CAR to the TRAC locus with CRISPR/Cas9 enhances tumour rejection. Nature 543: 113-117, 2017.

97. Mou H, Kennedy Z, Anderson DG, Yin H and Xue W: Precision cancer mouse models through genome editing with CRISPR-Cas9. Genome Med 7: 53, 2015.

98. MacLeod DT, Antony J, Martin AJ, Moser RJ, Hekele A, Wetzel KJ, Brown AE, Triggiano MA, Hux JA, Pham CD, et al Integration of a CD19 CAR into the TCR alpha chain locus streamlines production of allogeneic gene-edited CAR T cells. Mol Ther 25: 949-961, 2017.

99. Ren J, Zhang X, Liu X, Fang C, Jiang S, June CH and Zhao Y: A versatile system for rapid multiplex genome-edited CAR $\mathrm{T}$ cell generation. Oncotarget 8: 17002-17011, 2017.

100. Grupp SA, Laetsch TW, Buechner J, Bittencourt H, Maude SL, Verneris MR, Myers GD, Boyer MW, Rives S, De Moerloose B, et al: Analysis of a global registration trial of the efficacy and safety of CTL019 in pediatric and young adults with relapsed/refractory acute lymphoblastic leukemia (ALL). Blood 128: 221, 2016.

101.Zhao Z, Chen Y, Francisco NM, Zhang Y and Wu M: The application of CAR-T cell therapy in hematological malignancies: Advantages and challenges. Acta Pharm Sin B 8: 539-551, 2018.

102. Beatty GL, Haas AR, Maus MV, Torigian DA, Soulen MC, Plesa $\mathrm{G}$ and Kalos M: Mesothelin-specific chimeric antigen receptor mRNA-engineered $\mathrm{T}$ cells induce antitumor activity in solid malignancies. Cancer Immunol Res 2: 112-120, 2014.

103. Mirzaei HR, Rodriguez A, Shepphird J, Brown CE and Badie B Chimeric antigen receptors $\mathrm{T}$ cell therapy in solid tumor: Challenges and clinical applications. Front Immunol 8: 1850, 2017.

104. Boardman DA, Philippeos C, Fruhwirth GO, Ibrahim MA, Hannen RF, Cooper D, Marelli-Berg FM, Watt FM, Lechler RI, Maher J, et al: Expression of a chimeric antigen receptor specific for donor HLA class I enhances the potency of human regulatory T cells in preventing human skin transplant rejection. Am J Transplant 17: 931-943, 2017.

105. Shen CJ, Yang YX, Han EQ, Cao N, Wang YF, Wang Y, Zhao YY, Zhao LM, Cui J, Gupta P, et al: Chimeric antigen receptor containing ICOS signaling domain mediates specific and efficient antitumor effect of T cells against EGFRvIII expressing glioma. J Hematol Oncol 6: 33, 2013.

106. Owens GL, Sheard VE, Kalaitsidou M, Blount D, Lad Y, Cheadle EJ, Edmondson RJ, Kooner G, Gilham DE and Harrop R Preclinical assessment of CAR T-cell therapy targeting the tumor antigen 5T4 in ovarian cancer. J Immunother 41: 130-140, 2018.
107.Ellebrecht CT, Bhoj VG, Nace A, Choi EJ, Mao X, Cho MJ, Di Zenzo G, Lanzavecchia A, Seykora JT, Cotsarelis G, et al: Reengineering chimeric antigen receptor $\mathrm{T}$ cells for targeted therapy of autoimmune disease. Science 353: 179-184, 2016

108. O'Rourke DM, Nasrallah MP, Desai A, Melenhorst JJ, Mansfield K, Morrissette JJD, Martinez-Lage M, Brem S, Maloney E, Shen A, et al: A single dose of peripherally infused EGFRvIII-directed CAR T cells mediates antigen loss and induces adaptive resistance in patients with recurrent glioblastoma. Sci Transl Med 9: pii: eaaa0984, 2017.

109. Posey AD, Schwab RD, Boesteanu AC, Steentoft C, Mandel U, Engels B, Stone JD, Madsen TD, Schreiber K, Haines KM, et al: Engineered CAR T cells targeting the cancer-associated Tn-Glycoform of the membrane mucin MUC1 control adenocarcinoma. Immunity 44: 1444-1454, 2016

110. Burga RA, Thorn M, Point GR, Guha P, Nguyen CT, Licata LA, DeMatteo RP, Ayala A, Joseph Espat N, Junghans RP and Katz SC: Liver myeloid-derived suppressor cells expand in response to liver metastases in mice and inhibit the anti-tumor efficacy of anti-CEA CAR-T. Cancer Immunol Immunother 64: 817-829, 2015

111. Ahmed N, Brawley VS, Hegde M, Robertson C, Ghazi A, Gerken C, Liu E, Dakhova O, Ashoori A, Corder A, et al: Human epidermal growth factor receptor 2 (HER2)-specific chimeric antigen receptor-modified $\mathrm{T}$ cells for the immunotherapy of HER2-positive sarcoma. J Clin Oncol 33: 1688-1696, 2015.

112. Akce M, Zaidi MY, Waller EK, El-Rayes BF and Lesinski GB: The potential of CAR T cell therapy in pancreatic cancer. Front Immunol 9: 2166, 2018

113. Bach PB, Giralt SA and Saltz LB: FDA approval of tisagenlecleucel: Promise and complexities of a $\$ 475000$ cancer drug. JAMA 318: 1861-1862, 2017.

114. Fala L: Yescarta (Axicabtagene Ciloleucel) second CAR T-cell therapy approved for patients with certain types of large B-cell lymphoma. Am Health Drug Benefits 11: 109-111, 2018.

115. Hey SP and Kesselheim AS: The FDA, Juno therapeutics, and the ethical imperative of transparency. BMJ 354: i4435, 2016.

116. Rotolo A, Caputo V and Karadimitris A: The prospects and promise of chimeric antigen receptor immunotherapy in multiple myeloma. Br J Haematol 173: 350-364, 2016

117. Almond LM, Charalampakis M, Ford SJ, Gourevitch D and Desai A: Myeloid sarcoma: Presentation, diagnosis, and treatment. Clin Lymphoma Myeloma Leuk 17: 263-267, 2017.

118. Locke FL, Neelapu SS, Bartlett NL, Siddiqi T, Chavez JC, Hosing CM, Ghobadi A, Budde LE, Bot A, Rossi JM, et al: Phase 1 results of ZUMA-1: A multicenter study of KTE-C19 Anti-CD19 CAR T cell therapy in refractory aggressive lymphoma. Mol Ther 25: 285-295, 2017.

119. Qasim W, Ciocarlie O, Adams S, Inglott S, Murphy C, Rivat C, Wright G, Lucchini G, Silva J, Rao K, et al: Preliminary results of UCART19, an allogeneic anti-CD19 CAR T-cell product in a first-in-human trial (PALL) in pediatric patients with CD19+ relapsed/refractory B-cell acute lymphoblastic leukemia. Blood 130: 1271, 2017.

120. Cai T, Galetto R, Gouble A, Smith J, Cavazos A, Konoplev S, Lane AA, Guzman ML, Kantarjian HM, Pemmaraju N, et al: Pre-clinical studies of Anti-CD123 CAR-T cells for the treatment of blastic plasmacytoid dendritic cell neoplasm (BPDCN). Blood 128: 4039, 2016.

121. Gouble A, Schiffer-Mannioui C, Thomas S, Gautron AS Poirot L and Smith J: Abstract 3763: UCART22: Allogenic adoptive immunotherapy of leukemia by targeting CD22 with CAR T-cells. Cancer Res 77: 3763-3763, 2017.

122. Galetto R, Chion-Sotinel I, Gouble A and Smith J: Allogenic TCRa/CS1 double knockout T-cells bearing an anti-CS chimeric antigen receptor: An improved immunotherapy approach for the treatment of multiple myeloma. Cancer Res 76 (14 Suppl): Abstract nr 2289, 2016.

123. Drent E, Groen RW, Noort WA, Themeli M, Lammerts van Bueren JJ, Parren PW, Kuball J, Sebestyen Z, Yuan H, de Bruijn J, et al: Pre-clinical evaluation of CD38 chimeric antigen receptor engineered $\mathrm{T}$ cells for the treatment of multiple myeloma. Haematologica 101: 616-625, 2016.

124. Coulter I: Compositions. US Patent 2018/0228866A1. Filed August 12, 2016; issued August 16, 2018. 